\title{
Research on the Application of Digital Media Technology in Heritage Exhibit Design \\ Xiaofei Qiu
}

Address:School Of Design Of JiangHan University, WuHan, HuBei, China

Email:65801599@qq.com

\author{
Keywords: Digital Media Technology, Heritage, Exhibit, Application
}

\begin{abstract}
Digital media technology has been widely used in recent years in the field of cultural relics show, demonstrated in the enhanced performance, rich viewer experience, and strengthen information dissemination and exchange, the dramatic show, interest, participation, interaction, and played an important effect. Also, because without limitation abuse, misuse is widespread, affecting the cultural showcase of science and it is not conducive to effectively play display functions.
\end{abstract}

\section{Introduction}

In recent years, cultural relics on display, digital media technology plays a very important role, such as digital audio guide, interactive information systems, digital audio-visual, virtual reality and other technologies have become a common means of cultural impressions. According to statistics, in recent years, new artifacts on display (except for scientific and technological heritage), the actual investment in digital media exhibition to display items in about $15 \%$ of the total investment - the $25 \%$. But in the cultural industry, on how to apply digital media technology, applied to what extent, there is a big difference. A lot has been put into practical use to show the effect of digital media exhibited items are often unsatisfactory, mainly due to a lack of understanding between each other relics exhibition designers and digital media designers, the former unclear technical conditions required for the implementation and generated effects, which are not familiar with the characteristics and display artifacts show the need to achieve the purpose of dissemination. Thus, resulting in the overall display design heritage shows the status of traditional artificial split into two parts and digital media, and their own way in the planning and design and construction, for example, by a display design generally show the total package will be one of the digital media exhibition item subcontracted to professional digital media production company, neglect control and coordination exhibited items, and seriously undermined the overall effect of cultural relics show, only a waste of public cultural resources, is not conducive to give full play to the social function of cultural relics.

\section{The Limitations of Traditional Media in Display}

It Is Difficult to Show the Whole Picture Exhibits. Kind show viewers often only see a visual plane, even if only to show the center cabinet better observed plane 4 in the positive direction, while the upper, lower and observe some oblique direction is very difficult. Some flat display artifacts also often show one side, the other side is completely unable to see. In addition, some artifacts and specimens damaged or incomplete, it is difficult to achieve the desired effect when on display.

It Is Difficult to Show Detail. Large cultural entity display, viewers can only see general appearance, not easy to see the details of the internal structure and artifacts, such as the inside of the container process details and inscriptions. Small exquisite artifacts, the audience can not see the fine texture depicts or engraving. Such as national cultural relics of Tang Dynasty gold and silver bird grain honey aroma ball diameter of only $4.8 \mathrm{~cm}$, but outside there are fine arts gold ornamentation, the internal structure of complex, connected to the ring, and two hemispherical Hong $\mathrm{Yu}$, if combined incense ball, it can not show its internal structure, if the ball hit the incense, not easy to show when its surface ornamentation, the use of traditional media to show both difficult to balance. 
Single Sensory. Information contained in the exhibits artifacts on display are not all visual information, there are other sensory information hearing, smell, touch, sight, etc. other than through the traditional display mode would be difficult to achieve the purpose of dissemination of information. Dissemination of information on other senses other than vision, remains a major limiting factor in traditional media impressions. Currently a large number of cultural relics exhibition bell, chime, drums, piano and other instruments also confined to showcase its shape, decoration, the audience is not conducive to a comprehensive and accurate understanding of the information and its heritage value.

It Is Difficult to Show the Native Environment of Heritage. Archaeological items or artifacts, specimens native environment contains a wealth of historical, scientific information, has an important academic value, is an important basis for the audience to understand the exhibits. But the show entered the cultural exhibits categorized, then the organization has lost its native environment information, become orphaned objects. For example, an ancient tombs unearthed cultural relics, the show often follow cultural texture, correlation of each display, the original stacked relationship, package and location information is not performance. Even through the plate, it is difficult to fully model intuitively that information reproduced.

\section{The Features and Advantages of the Digital Media}

Comprehensively Display the Exhibits Information. For display three-dimensional object, you can show all sides of the rotation of objects, can also transform the internal perspective, usually invisible part of the display. As the capital of gilt bronze Buddha exhibition, on the use of three-dimensional model mapping, which allows viewers to operate each side to change the angle of rotation, see the statue. In addition, the technology can also be enhanced by means of three-dimensional visual experience a sense of the audience. In addition, three-dimensional holographic projection can exhibit space in a dynamic three-dimensional object, giving the audience a visual experience.

Enhance the Showing Details of Performance. Through digital media technology virtual deconstruction of large artifacts, exhibits artifacts enlarged close-up site, high-definition display of strokes of calligraphy and paintings, seal and other fine features, the audience clearly see the texture of the exhibits, depicting, detail carving. We can better compensate for the inconvenience of physical display close observation, inadequate lighting showrooms and lack sufficient detail defects. Such as the Palace Museum website painting exhibition, painting and calligraphy exhibition will be scanned by high-definition network presented to the audience, you can zoom in on specific parts of any of the exhibits, not only 1: 1 to show the original painting, the picture can be enlarged several times, showing the effect of far better than the physical display in the exhibition hall, can be said that a good solution to the conflict between heritage conservation and display.

It Has Diverse Sensory Information Dissemination. Single visual communication compared to traditional display, the use of digital media technology to convey a richer display of information through other senses of hearing, touch, and other visual outside. So show no longer confined to "see", but a look, listen, touch, can feel the show.

It Is Easy to Display the Native Environment of Relics. For example, in Chinese ancient ship relics (construction) show ancient ship, the canopy Lai small sea, the ancient ship in the sea before the water is what state? What kind of environment is it? Since the built heritage wreck near the sea, exhibition space located in the underground space under the sea level, and therefore can be used to show a large projection to simulate seabed for small viewing window on the sea wall, you can see the ancient ship before the water stored in the bottom of the sea through the window status and surrounding environment.

The Information Capacity Is Large. Traditional display large amounts of information subject to the limitations in the exhibition area and space cannot or is not easy to show digital media can be easily achieved by the membership. You will need to provide a large number of visitors to the chart, the use of digital media in the form of text into the computer, for the viewer to choose a browser. You can also create information system to facilitate the audience more convenient and fast way to 
query, access to information. The use of digital media technology to provide information to show exhibition space without restriction (information system footprint is negligible compared with the conventional plates, and the amount of information that can be loaded with information systems theory is unlimited), which greatly saves display space, but also to avoid excessive unorganized plate caused by such dissemination of information is more targeted. For example, touch screen inquiry system exhibits artifacts on display are widely used, can provide viewers with exhibits details and background information, to facilitate understanding of the audience's knowledge of the exhibits.

\section{The Current Problems of Digital Media Technology}

The Form and Content of Expansion Is Not Uniform. Artifacts on display there, regardless of the current situation, the trend of abuse of new technologies regardless of conditions, some of the digital media exhibition without clear demonstration purposes, for the application and the application, literally put a variety of new media technology that is placed to show some of the , it undermines the structure of clues and impressions. Ideal demonstration projects should be closely integrated content and form, through digital media in the form completely and accurately convey the show content. However, in practical applications often visible form and content is almost irrelevant exhibition items, often to a certain kind of technology to the different display content. As ever fad interactively screen projection, with regard to the various guises in many cultural relics on display, and the contents of the display is often not associated, it is extremely far-fetched.

Part of the Performance Content Is Created out of Thin Air and There Is Common Mistake. Good digital media display is scientific, rigorous content plus a reasonable basis, there is constituted in accordance with the imagined, if the lack of support for academic research and image data, but baseless fabrications and interpretation, even obvious mistakes, not only cannot achieve what you want to convey to show serious damage to scientific and educational shows, the impact of public image artifacts. For example, some artifacts movie clips directly from the part of the lens film, television, no relevant facts and details of academic research and cultural heritage does not meet the required spread of scientific accuracy.

The System Software and Hardware Set Is Unreasonable. Devices or digital media content items arranged exhibition display inappropriate environment or the environment is not well integrated into the exhibition hall, showing the effect of the impact, it is awkward and stiff, such as setting the phantom imaging in a bright hall environments that require low light environment the exhibited items, set in ancient simulation scenario artistic design without modern equipment processing; otherwise: dynamic performance facility stiff; interactive equipment difficult to operate; poor theater viewing angle; exhibited items in each subsystem with the lack of coordination; film production raw sugar, the screen brightness is insufficient, the image quality is not clear, may not play smoothly, sound unnatural and so on, resulting in a practical demonstration of the effect cannot be expected.

The Showing Device Intact Rate Is Low. More generally it relic on display digital media exhibition item fails in use for some time after, or even damage, becoming the exhibition hall furnishings. As the exhibition hall of the touch screen failure, sound fails, the server response is slow, frequent crashes, the projector is out of focus, offset positioning, the lamp brightness decay, interactive facility failure, dynamic presentation content is not synchronized with the device.

\section{The Rational Application Principles of Digital Media in Display}

The Form and Content is Unity. The first principle in digital media technology artifacts on display is to show the application form and content to achieve a high degree of unity. In the past, the industry is generally believed that the form of artifacts to show absolute obedience to the content, which is the traditional media to show the art of landscaping, decorative purposes, but in the digital media display, the distinction between form and content and not a clear line, but you have me, I have you, precisely, is a relationship with each other. 
The Show Obeys the Purpose. Design digital media exhibited items should be subordinated to the theme and show the purpose of dissemination. In practice, the theme often found in digital media artifacts exhibited items, although novelty, fun, but completely divorced display outside, people talking. This exhibition not only would not achieve the proper term role in disseminating, it undermines the integrity of the show, the audience's attention interference. So in terms of digital media planning exhibition design, it must bear the purpose of dissemination withhold show, not to join the digital media elements throughout the show and barely used. Digital media throughout the show is not necessary, if the relationship is not content with the show, cannot play the role to enhance the display of results, you need to use. Final evaluation of the success of a show, does not depend on the use of new technology, new media, but on the right shows whether the intention to achieve a curators, to achieve the desired purpose of dissemination.

Adhere to Rigorous Scientific Principles. During display of digital media creation, we should always adhere to the scientific rigor to show content. Heritage Gallery is a means of dissemination of scientific knowledge of education, which is its number-font display and theme parks, playgrounds, cinemas difference lie. This requires that the relevant exhibition items must be fully rigorous academic support system, accurate, vivid, complete expression of scientific knowledge, historical truth to be spread, and cannot concoct false, there is no content. The reason why some artifacts show was criticized for excessive "entertainment", because it is too far in pursuing the effect of gorgeous, scene stimulation, while ignoring the real objective content. Display design should be entertaining, but definitely not out of the fact that other than pure entertainment.

\section{Conclusions}

The rapid development of digital media technology, new technologies, new methods emerging, such as phantom imaging, augmented reality, semi-dynamic landscape painting, etc., it is impossible to enumerate. Digital media design heritage exhibition item, the "Buddha is not fixed," each item has a unique exhibition of the purpose of dissemination and academic support material, during the time of project design, or according to the specific design of the actual situation, the paper cited the case for reference only.

\section{References}

[1] Ruohan Zhou: Chinese Cultural Relics, Vol. 6 (2004) No 53, p.25-26

[2] Bo Xu: Heritage World, Vol. 12 (2005) No 27, p.74-76

[3] Qin Guo: Chinese Cultural Relics, Vol. 1 (2006) No 33, p.11-14

[4] Jieming Liu: Guangxi Normal University, Vol. 3 (2007) No33, p.121-124

[5] http://www.bmnh.org.cn/web/cn/kyysc/zwxyj/zwxyjnr/1940/200709056231.html,2007-9-3 